\title{
Los barberos flebotomianos y el Quijote
}

\author{
Phlebotomist barbers and the Quixote
}

\author{
Martha Díaz Gómez*
}

\begin{abstract}
Como homenaje a
Don Miguel de Cervantes Saavedra en el 400 aniversario del fin de su fecunda vida

En la prolífica obra de don Miguel de Cervantes Saavedra, sin duda alguna el escritor de mayor trascendencia en lengua castellana de todos los tiempos, hay reiteradas referencias a la salud, enfermedades, tratamientos médicos, quirúrgicos y referencias dentales. Lo que indica que Cervantes sabía sobre medicina y dentistería mucho más de lo habitual en los ciudadanos de su época, colocándolo como un autor de gran relevancia para el conocimiento de las prácticas dentales del siglo XVI y principios del XVII, época en la que la odontología aún no se consolidaba como una profesión científica, estructurada e independiente. Los tratamientos de las afecciones dentales estaban en manos de cirujanos y de los llamados barberos flebotomianos
\end{abstract} sacamuelas.

\section{EL OFICIO DE BARBERO FLEBOTOMIANO}

Desde la Baja Edad Media en toda Europa proliferaron individuos dedicados a efectuar flebotomías y algunos otros procedimientos quirúrgicos, como abrir abscesos y realizar extracciones dentales, todos ellos ejercían sin ningún tipo de control ni estudios universitarios. En España el oficio de los barberos flebotomianos se reglamentó hasta mediados del siglo XV, y a los «Barberos Mayores del Rey» se les encomendó la redacción de las ordenanzas del oficio y también la facultad de concederles el poder a los alcaldes examinadores en todo el reino para hacer lo propio. Debido a la gran población que necesitaba de estos servicios, el número de barberos flebotomianos iba en aumento y eran pocos los que acataban las ordenanzas, razón por la que en 1500 se dictó una disposición provenien-

\footnotetext{
${ }^{1}$ Rocha Garfias Vanesa Pág. 72.

${ }^{2}$ Así se le llamaba al lugar en donde ejercían el oficio.
}

te de los reyes Isabel y Fernando, con los siguientes señalamientos: ${ }^{1}$

\begin{abstract}
«Mandamos que los Barberos Examinadores Mayores de aquí en adelante no consientan ni den lugar que ningún barbero, ni otra persona alguna pueda poner tienda para sangrar, ni echar sanguijuelas, ni ventosas, ni sacar dientes ni muelas, sin ser examinados por los dichos nuestros Barberos Mayores...»
\end{abstract}

Aquellos que aprobaban, obtenían su «carta de examen» documento que tenían que mostrar a las autoridades competentes para poder abrir su «tienda de barbero". ${ }^{2}$

Los había que ejercían en sus domicilios, otros se instalaban en plazas públicas, mercados, caminos e incluso llegaban a ser asalariados de familias, nobles y uno que otro figuraba en la nómina del rey.

En 1557 ocurrió algo de gran trascendencia para los quehaceres dentales, la publicación del primer libro escrito en español que trata exclusivamente de afecciones de la cavidad oral, sus causas y tratamientos. El autor fue el médico Francisco Martínez del Castrillo, quien escribió esta obra preocupado por la práctica tan deficiente de los cirujanos y barberos flebotomianos sacamuelas y la rivalidad que existía entre éstos y los médicos con título universitario. Martínez del Castrillo fue un médico culto y preparado cuya buena fama le valió recibir el nombramiento de médico de la boca de Felipe II de España. En la obra el autor vierte innovadores conceptos sobre: anatomía, función de los dientes, caries y enfermedades del periodonto, prótesis y

\footnotetext{
* Departamento de Historia, Facultad de Odontología, UNAM.

(C) 2016 Universidad Nacional Autónoma de México, [Facultad de Odontología]. Este es un artículo Open Access bajo la licencia CC BY-NC-ND (http://creativecommons.org/licenses/by-nc-nd/4.0/).
}

Este artículo puede ser consultado en versión completa en http://www.medigraphic.com/facultadodontologiaunam 
sorprendentes ideas sobre prevención. El «Coloquio breve y compendioso sobre la materia de la dentadura y la maravillosa obra de la boca» influyó de manera importante en la España Renacentista. ${ }^{3}$

Varios biógrafos de Miguel de Cervantes creen que éste tuvo que haber conocido el contenido de tan importante tratado, ${ }^{4}$ ya que sus inquietudes intelectuales eran más que evidentes y el tema de los dientes le interesó toda la vida.

\section{MIGUEL DE CERVANTES SAAVEDRA Y SUS REFERENCIAS DENTALES}

En todas las obras que escribió, Cervantes pone de manifiesto su familiaridad con la práctica médico quirúrgica que vivió en su entorno familiar, ya que existen sobradas razones para asegurar que su padre Rodrigo de Cervantes dedicó, gran parte de su vida laboral, al ejercicio de la cirugía, específicamente a tratar problemas dentales.

En un importante número de escritos de la llamada «Documentación Cervantina» Don Rodrigo de Cervantes se ostenta como médico cirujano, como en la carta con fecha del 30 de octubre de 1565 en donde da poderes a su esposa Leonor de Cortinas, madre del escritor y de su sobrino Andrés, para cobrar un adeudo, posiblemente por trabajos realizados en este oficio. Esta suma debía de recibirla su esposa o sobrino, debido a que él se ausentaría de casa.

Don Miguel provenía de una familia de hidalgos: su abuelo materno, don Juan Díaz de Torreblanca era cirujano de profesión, mientras que por el lado paterno, don Juan de Cervantes fue hombre cultivado e influyente, pues se licenció en leyes y se movía en un círculo de letrados médicos, clérigos y profesores universitarios.

La familia formada por don Rodrigo de Cervantes y Doña Leonor de Cortinas vivió en Alcalá de Henares, en donde nacieron tres niñas: Andrea, Luisa, Magdalena y dos varones Miguel y Rodrigo. A los 21 años Miguel, en compañía de su hermano se alistó en el ejército para partir rumbo a Nápoles, en donde ambos se embarcarían en la galera "La Marquesa», que como parte de la armada española muy pronto le tocaría participar en la batalla de Lepanto, contra la flota otomana. A esta edad, Miguel de Cervantes ya había aprendido de su padre todo acerca del oficio de barbero-sangrador-sacamuelas, y en el barco tendría contacto con los individuos dedicados a la atención

\footnotetext{
${ }^{3}$ Esponda G, Víctor y Aguilar L, Lourdes Pág. 43-48.

${ }^{4}$ Antonio del Valle González Pág. 76.

${ }^{5}$ Receta.
}

de marinos, soldados y oficiales. Es comprensible que Miguel de Cervantes sintiera afinidad con ellos.

Durante la citada batalla, Miguel de Cervantes fue herido de arcabuz en el brazo izquierdo y en el tórax. Posterior a la victoria, la flota española regresó a tierras italianas y Miguel fue a dar al Hospital de Mesina, en donde, debido a la gravedad de las heridas, permaneció año y medio. Durante este tiempo tuvo contacto muy directo con médicos y cirujanos, pudiendo observar el trabajo de éstos. Realmente las desventuras de los hermanos Cervantes principiaron durante su regreso a España, pues durante el trayecto de Nápoles a puerto español, el barco fue capturado por piratas que los llevaron presos a Argelia. La permanencia en cautiverio fue de cinco años, en los que los hermanos hicieron varios intentos vanos para escapar. Los años que permaneció en cautiverio los compartió con otros desventurados, entre los que se encontraba un doctor en filosofía de apellido Sosa con quien Miguel estableció una buena amistad. Mientras tanto los padres reunieron todo el dinero posible para pagar el rescate, vendieron sus pocas propiedades y al fin lo lograron la libertad de sus hijos.

A su regreso a España Miguel de Cervantes empezó a escribir y en sus textos menciona para bien o para mal a los médicos que conoció en sus correrías. En «El canto de Calíope» nombra a los doctores: Campuzano, Vaca, Francisco Díaz y al licenciado Juan de Vergara, médico, cirujano y poeta en la siguiente octava:

$$
\begin{aligned}
& \text {...El alto ingenio y su valor declara } \\
& \text { un licenciado tan amigo vuestro } \\
& \text { cuanto ya sabéis que es Juan de Vergara, } \\
& \text { honra del siglo venturoso nuestro... }
\end{aligned}
$$

También, en ocasiones lanza severas críticas a los médicos de mala práctica a los que se refiere como médicos de segunda:

...Sólo los médicos nos pueden matar y nos matan sin temor y a pié quedo, sin desenvainar otra espada que la de un récipe... ${ }^{5}$

Reconoció, en muchas ocasiones, el gran valor que tienen los dientes, por ejemplo, cuando Don Quijote, dolido por la pérdida de varias muelas a causa de la pedrada que le propinó un pastor, le dice a Sancho:

«Te hago saber Sancho, que la boca sin muelas es como molino sin piedra y en mucho más se ha de estimar un diente que un diamante.»

Y sabemos que el mismo Miguel de Cervantes sufrió la pérdida de dientes, por la descripción que Don Miguel hace de sí mismo en donde muestra su preocupación por su nada envidiable dentadura: 
Este que veis aquí, de rostro aguileño, de cabello castaño, frente lisa y desembarazada, de alegres ojos y de nariz corva, aunque bien proporcionada; las barbas de plata, que no ha veinte años que fueron de oro, los bigotes grandes, la boca pequeña, los dientes ni menudos ni crecidos, porque no tiene sino seis, y esos mal acondicionados y peor puestos, porque no tienen correspondencia los unos con los otros; llamase comúnmente Miguel de Cervantes Saavedra

En algunos dichos utilizados a lo largo de la novela, Cervantes utiliza términos dentales, como el que pone en boca de Sancho, que gusta de los refranes:

«Entre dos muelas cordales nunca pongas tus pulgares", refiriéndose a que no hay que enfrentarse a personas más poderosas, porque se saldrá perdiendo.

Uno de los personajes importantes de El Quijote es el maese Nicolás, que era el barbero sacamuelas de la aldea en donde vivía el ilustre hidalgo. De hecho el caballero andante se coloca sobre la cabeza, a manera de sombrero, la bacía de un barbero, poniendo en evidencia el conocimiento que tenía de los implementos que estos personajes utilizaban. Muy posiblemente se inspiró en su padre para crear a este personaje.

En la época de Cervantes el culto a Santa Apolonia era muy difundido y las personas que sufrían dolores dentales le rezaban, para que los auxiliara. En la segunda parte de la novela hay una referencia a la santa, cuando un personaje, preocupado por las locuras de Don Quijote, le sugiere a la persona que le sirve, que de camino a su casa fuera rezándole a Apolonia. A lo que ella contesta:

«Eso fuera si mi amo lo hubiera de las muelas, pero no lo ha sino de los cascos.»
Las referencias dentales plasmadas en el Quijote y por supuesto en otras novelas del escritor, aluden también a la limpieza dental, mencionando en varias ocasiones el momento en que algún hidalgo, después de comer, sacaba del bolsillo un monda-dientes, que podía ser de oro o plata, o simplemente un palillo de madera y limpiaba su dentadura de los restos de alimento ahí atrapados. Esto en aquella época no era mal visto y se consideraba una buena costumbre.

«El ingenioso Hidalgo Don Quijote de la Mancha» sin duda la primera novela de la literatura moderna universal y por supuesto la de mayor trascendencia en lengua castellana de todos los tiempos, es además una inagotable fuente de información sobre la España de fines del siglo XV y principios del XVI: expresiones idiomáticas, costumbres, ambientes, relaciones interpersonales, ideas, creencias, y para nosotros, interesados en la historia de la odontología, una verdadera joya.

\section{LECTURAS RECOMENDADAS}

- del Valle-González A. La odonto-estomatología y el campo semántico de la boca en la vida y obra de Miguel de Cervantes Saavedra, aportaciones a la historia de la odontología de la época [Tesis doctoral]. Madrid, España: Departamento de Estomatología y Embriología Humana, Facultad de Ciencias de la Salud, Universidad Rey Juan Carlos; 2010.

- Esponda V, Aguilar L. Odontología del siglo XVI y la obra de Francisco Martínez del Castillo. En: Historia de la odontología inicio y desarrollo en México. México: Ed. Odontología Books; 2015.

- Rocha-Garfias V. Barberos y flebotomianos en el México Colonial. En: Historia de la odontología inicio y desarrollo en México. México: Ed. Odontología Books; 2015.

- Sanz-Serrulla J. La odontología en tiempos de don Quijote. Pontevedra, Punto de encuentro N 12 julio 2005.

Dirección para correspondencia:

Martha Díaz Gómez

E-mail: diazkuri@gmail.com 